\title{
Finite element analysis of wheel/rail squeal noise
}

\author{
B. C. Goo \\ New Transportation Research Team, \\ Korea Railroad Research Institute, Korea
}

\begin{abstract}
Wheel/rail squeal noise of trains gives passengers a very unpleasant feeling. But a successful solution to the squeal problem has not been presented until now. In this study, to find out the basic mechanism of the wheel/rail squeal noise, complex eigenvalue analysis by finite element method was adopted as a numerical tool. The positive real parts of the eigenvalues mean the self-exciting instability of the vibration, which is closely related to the occurrence of squeal noise. The effect of parameters such as friction coefficient, wheel/rail contact position, axle load, etc. was examined. It was found that the applied method could simulate unstable modal shapes of the wheel/rail vibration and be used as a good tool for the study of wheel/rail squeal noise.
\end{abstract}

Keywords: wheel, rail, squeal, finite element, complex eigenvalue, friction, instability, contact.

\section{Introduction}

Squeal noise from wheel/rail and brake disc/pad frictional contact is typical in railways. Several hypotheses have been made and examined to explain the mechanism of squeal noise occurrence. The stick-slip hypothesis is well-known. According to this theory, the decrease of friction coefficient with slippage can generate a negative damping in a structure, which can induce self-exited unstable vibration. But Eriksson and Jacobson [1] showed that under stick-slip conditions, squeal did not occur. By North [2], under constant dynamic friction coefficient two neighbouring stable eigenmodes could converge to an unstable mode by varying the parameters of the system. This kind of instability is referred to as flutter instability. Spur [2] asserted that repetitive 'sprag-slip' was the cause of 
the squeal. On the other hand, Rhee et al. [3] explained that unstable vibration occurred by hammering effect due to local defects in the contact area. In recent years, with rapid progress of computer capabilities and numerical algorithms, many researchers have applied finite element method to analyse flutter instability in brake disc/pad [4-11]. In wheel/rail squeal, several experimental studies have been done [12-21], finite element analysis for the flutter instability has not been performed much. Chen et al [22] used spring elements to model the contact between wheel and rail when analysing the complex eigenvalues of wheel/rail contact problem.

In this study, the flutter instability was assumed to be the cause of the wheel/rail squeal. To estimate the instability of the wheel/rail system, traditional complex eigenvalue analysis by finite element was used. To consider the real contact between wheel and rail, three dimensional contact between wheel and rail was analysed.

\section{Finite element modelling}

\subsection{Procedure of the squeal analysis by finite element}

When damping is neglected, the eigenvalue problem of a vibration system is expressed as:

$$
\left(\lambda^{2}[M]+\lambda[C]+\left[K-K_{f}\right]\right)\{y\}=\{0\}
$$

where $[M],[C],\left[K-K_{f}\right]$ are the mass, damping and stiffness matrices, respectively. $\lambda$ is the eigenvalue. $\{y\}$ is the eigenvector. $[K]$ is the stiffness matrix originated from the structure itself. $\left[K_{f}\right]$ is the stiffness matrix from the contact force. $[K]$ is symmetric. But friction between wheel and rail or brake disc and pad makes $\left[K_{f}\right]$ asymmetric. Eigenvalues of eqn. (1) may have complex eigenvalues. When the real parts of the eigenvalues are positive, the system is unstable. The unstable modes are prone to generate squeal noise. The procedure of obtaining the complex eigenvalues is as follows:

1) Wheel/rail contact analysis under axle loading without consideration of friction between wheel and rail.

2) Taking the solution of the first step as initial values, perform friction analysis by the wheel slippage.

3) Find eigenvalues of the system without considering the damping and friction.

4) Finally find complex eigenvalues using the eigenmodes in the previous step as a subspace.

All analyses were carried out by ABAQUS Code [23], which provides the function to solve complex eigenvalue problems.

\subsection{Finite element modelling}

Fig. 1 presents the model of the wheelset and rail for finite element analysis. They are used in subway trains in Korea. The configurations are very similar to 


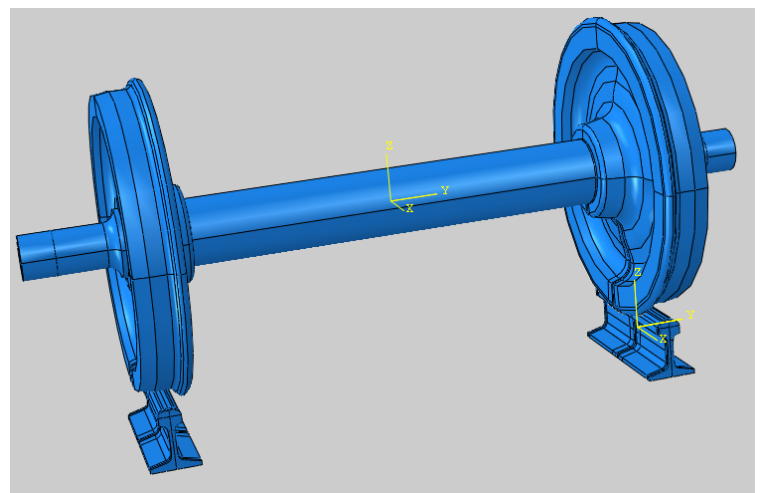

Figure 1: Finite element model of the wheelset and rails.

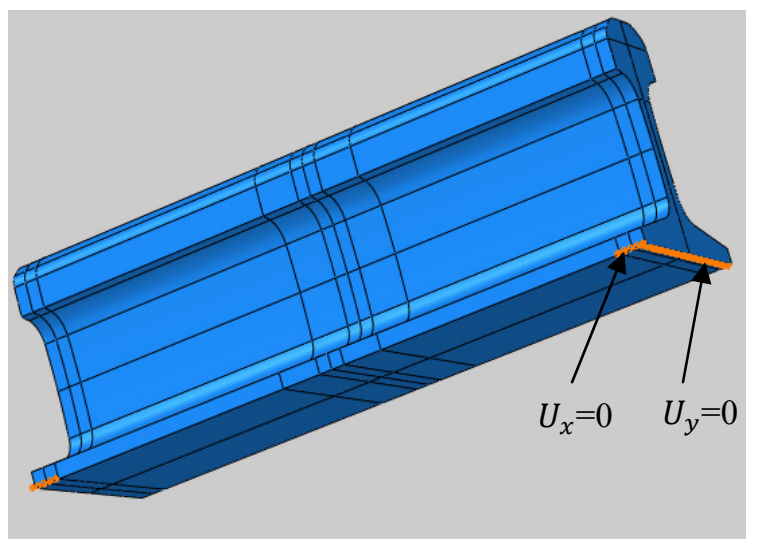

Figure 2: Boundary conditions on the rail.

those of UIC Code. The wheel tread has a 1:40 slope. For simplicity, all components installed on the axle were neglected. When analysing the dynamic characteristics of a wheel/rail system, it is difficult to model the rail properly. Here in the light of the distance between two neighbouring sleepers, a rail of $500 \mathrm{~mm}$ long is included in the model. Fig. 2 shows the boundary conditions on the rail. Besides the boundary conditions, the wheelset and rails were restrained by springs. The connection between the wheelset and the axle box were modelled by radial springs $\left(K_{x-a}, K_{y-a}\right.$ in fig. 3(a)). The spring constant was $K_{x-a}=K_{y-a}=10^{5} \mathrm{~N} / \mathrm{mm}$. In vertical direction the wheelset was constrained by the wheel/rail contact only. The vertical load, $F$, by the car body was applied at the centre points of the axle bearing seat on the axle (fig. 3(a)). $6000 \mathrm{~kg}_{\mathrm{f}}$ at both points was applied. To simulate similarly the stiffness of a real rail installed in the track, the rails were also constrained by springs in the both end sections 
(fig. 3(b)). The bottom face of each rail was supported by 51 vertical springs at each end section, and the side face was supported by $\mathrm{x}$-, y-directional 115 springs. The static and dynamic behaviour of the wheel/rail depends on the boundary conditions and the constraints by springs. So the analysis was performed for various spring constants. The size of the elements in the contact area was in the range of $0.5-1 \mathrm{~mm}$. Linear tetrahedral elements were used. The number of elements was 314,367 for the wheelset, and 63,698 for each rail.

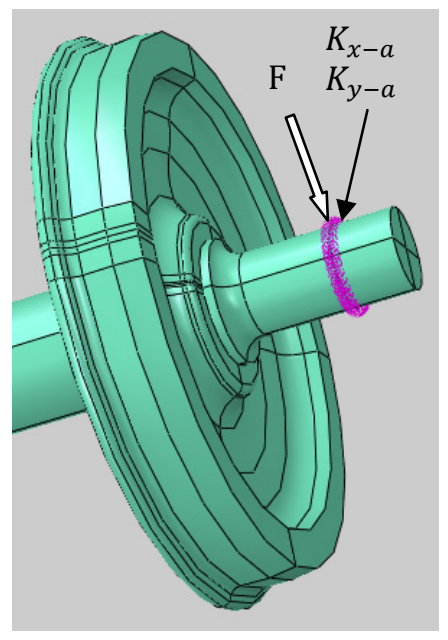

(a) Wheelset

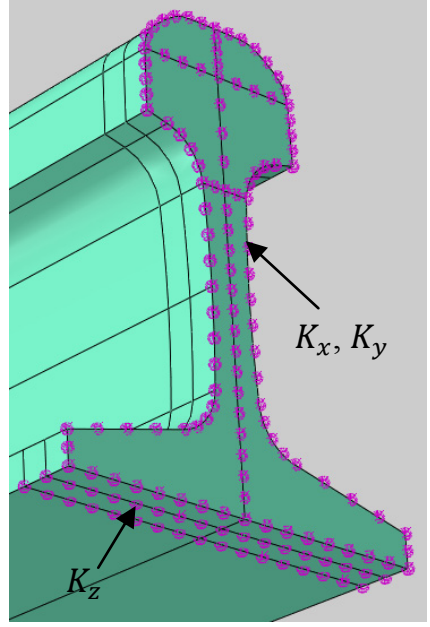

(b) rail

Figure 3: Constraints of the wheelset and rail by springs.

Table 1: Material properties.

\begin{tabular}{|c|c|c|}
\hline & Wheelset & Rail \\
\hline Elastic modulus $(\mathrm{GPa})$ & 206 & 206 \\
\hline Poisson ratio & 0.3 & 0.3 \\
\hline Density $\left(\mathrm{g} / \mathrm{cm}^{3}\right)$ & 7.85 & 7.85 \\
\hline Number of element & Linear tetrahedral, & Linear tetrahedral, \\
& 314,367 & $63,698 \times 2$ \\
\hline
\end{tabular}

\section{Results}

Fig. 4 shows the contact stress distribution when the spring constants on the rail are $K_{x}=K_{y}=1000 \mathrm{~N} / \mathrm{mm}$, and $K_{z}=10000 \mathrm{~N} / \mathrm{mm}$. The friction coefficient between the wheel and rail is $\mu=0.35$. Fig. 4 (a) is the von-Mises stress in the contact region under the vertical load only (Aforementioned analysis step 1). It is found the stress distribution is very similar to that of a classical Hertzian contact 
of two objects. Fig. 4(b) shows stress after the frictional force by slippage was applied additionally (Analysis step 2). To simulate this frictional contact behaviour, pseudo-movement of all the nodes of the rail in the lateral direction was given [23]. Because of the frictional load, the area with maximum stress in the wheel moved to the right. On the contrary, the high stress field in the rail moved to the left. Fig. 5 shows the unstable modal shapes. Two unstable modes occurred at frequencies 115.56 , and $1279.0 \mathrm{~Hz}$. Fig. 6 is the result when $\mu=0.43$ and the same spring constants were applied. In this case three unstable modes occurred at $114.41,1196.0$ and $1278.3 \mathrm{~Hz}$. The results obtained under various conditions were summarized in figs. 7,8 and table 2.

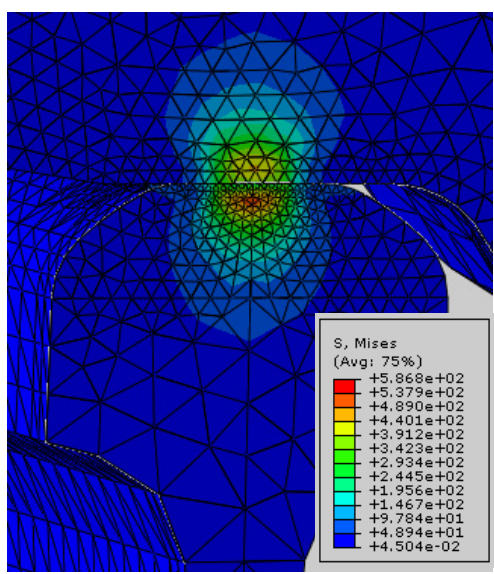

(a) Vertical load

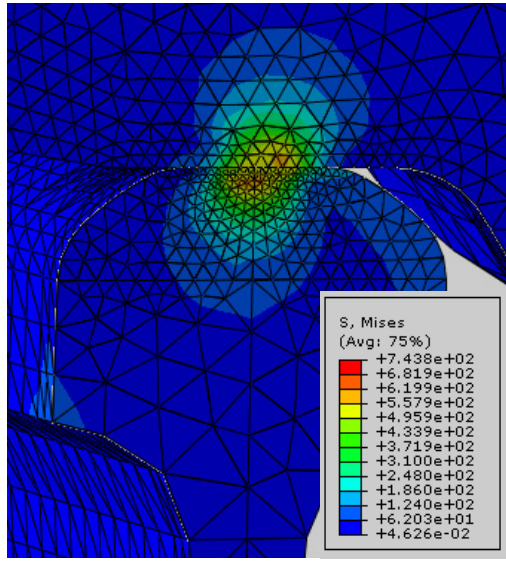

(b) Vertical and frictional load

Figure 4: von Mises stress distribution.

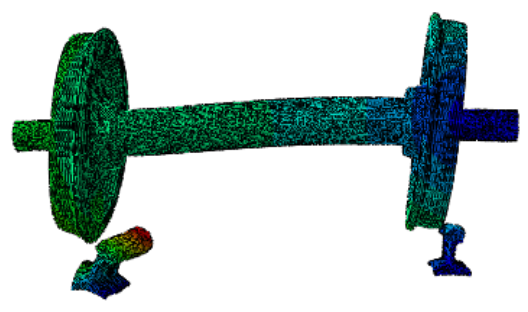

(a) $115.56 \mathrm{~Hz}$

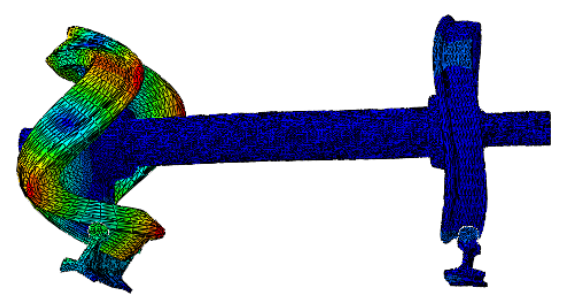

(b) $1279.0 \mathrm{~Hz}$

Figure 5: Flatter instability, $K_{x}=K_{y}=1000 \mathrm{~N} / \mathrm{mm}, K_{z}=10000 \mathrm{~N} / \mathrm{mm}$, $\mu=0.35$. 


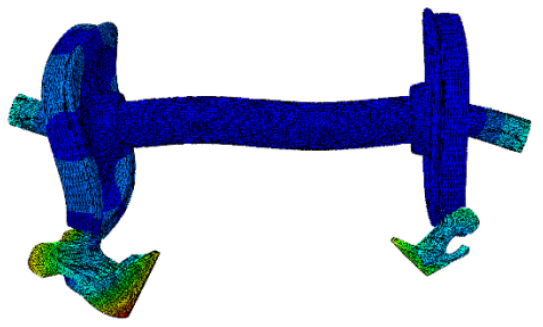

(a) $1196.3 \mathrm{~Hz}$

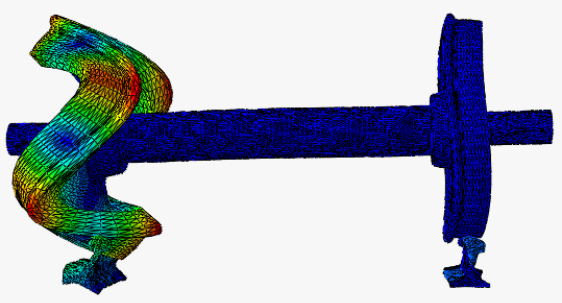

(b) $1278.3 \mathrm{~Hz}$

Figure 6: Flatter instability, $K_{x}=K_{y}=1000 \mathrm{~N} / \mathrm{mm}, \quad K_{z}=10000 \mathrm{~N} / \mathrm{mm}$, $\mu=0.43$.

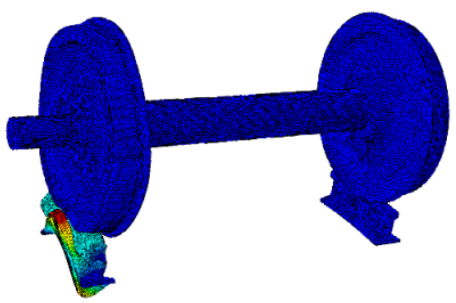

(a) $196.3 \mathrm{~Hz}$

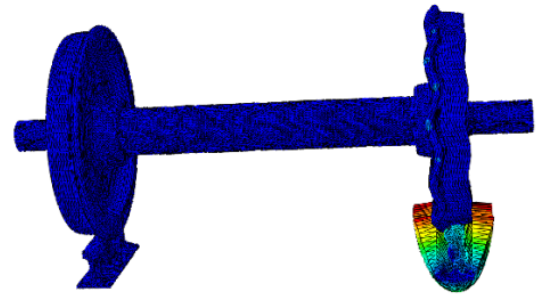

(b) $1278.3 \mathrm{~Hz}$

Figure 7: Flatter instability, $K_{x}=K_{y}=10^{4} \mathrm{~N} / \mathrm{mm}, K_{z}=10^{8} \mathrm{~N} / \mathrm{mm}, \mu=0.33$.

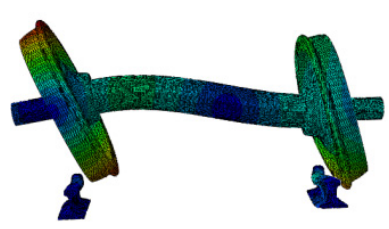

(a) $217.68 \mathrm{~Hz}$

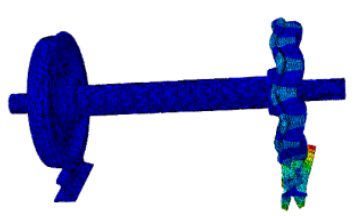

(b) $6916.0 \mathrm{~Hz}$

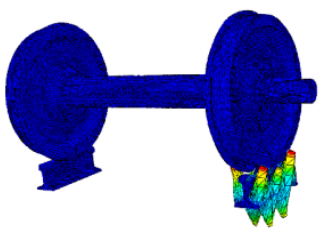

(c) 9396.9

Figure 8: Flatter instability, $K_{x}=K_{y}=K_{z}=108 \mathrm{~N} / \mathrm{mm}, \mu=0.35$. 
Table 2: Flutter instability under various conditions.

\begin{tabular}{|c|c|c|c|c|}
\hline \multicolumn{2}{|c|}{$\begin{array}{l}\text { Rail supporting spring } \\
\text { constant, } K\end{array}$} & \multirow{2}{*}{$\begin{array}{c}\text { Friction } \\
\text { coefficient, } \\
\mu\end{array}$} & \multirow{2}{*}{$\begin{array}{c}\text { Vertical } \\
\text { load } \\
\left(\mathrm{Kg}_{\mathrm{f}}\right)\end{array}$} & \multirow{2}{*}{$\begin{array}{l}\text { Unstable modal frequency } \\
\qquad(\mathrm{Hz})\end{array}$} \\
\hline $\begin{array}{c}K_{x}=K_{y} \\
(\mathrm{~N} / \mathrm{mm})\end{array}$ & $\begin{array}{c}K_{z} \\
(\mathrm{~N} / \mathrm{mm})\end{array}$ & & & \\
\hline 1000 & 10000 & 0.09 & 12000 & None \\
\hline 1000 & 10000 & 0.10 & 12000 & 1280.2 \\
\hline 1000 & 10000 & 0.20 & 12000 & 1277.5 \\
\hline 1000 & 10000 & 0.31 & 12000 & $116.24,1278.9$ \\
\hline 1000 & 10000 & 0.35 & 12000 & $115.56,1279.0$ \\
\hline 1000 & 10000 & 0.37 & 12000 & $115.17,1278.0$ \\
\hline 1000 & 10000 & 0.40 & 12000 & $114.78,1278.8$ \\
\hline 1000 & 10000 & 0.43 & 12000 & $114.32,1196.3,1278.3$ \\
\hline 1000 & 10000 & 0.45 & 12000 & $114.15,1197.1,1279.9$ \\
\hline 1000 & 10000 & 0.47 & 12000 & $\begin{array}{c}113.76,1197.6,1278.9, \\
5520.8\end{array}$ \\
\hline 1000 & 10000 & 0.35 & 10000 & $\begin{array}{c}114.95,1192.5,1272.5, \\
6423.1\end{array}$ \\
\hline 1000 & 10000 & 0.35 & 14000 & $116.09,1284.1$ \\
\hline 10000 & $10^{8}$ & 0.35 & 12000 & $212.67,2217.2,10675$ \\
\hline 50000 & $10^{8}$ & 0.35 & 12000 & 214.23 \\
\hline $10^{5}$ & $10^{7}$ & 0.35 & 12000 & $215.26,9403.7$ \\
\hline $10^{8}$ & $10^{8}$ & 0.35 & 12000 & $217.68,6916.0,9396.9$ \\
\hline $10^{8}$ & $10^{8}$ & 0.12 & 12000 & None \\
\hline
\end{tabular}

\section{Conclusions}

In this study, the wheel/rail instability by lateral slippage was simulated successfully by the complex eigenvalue approach. It was found the unstable modes were dependent on the friction coefficient, vertical load and the boundary conditions applied to the rails. The unstable modes obtained at low, middle and high frequencies were reasonable compared to the test results in the literature. To simulate more correctly the instability of wheel/rail by slippage, it seems that the vibrational behaviour of the rails installed in track should be measured and imported to the modelling.

\section{Acknowledgements}

This research was supported by a grant (13-RTRP-B072484-01) from Railroad Technology Research Program funded by the Ministry of Land, Infrastructure and Transport of Korean government. 


\section{References}

[1] Eriksson, M. \& Jacobson, S., Friction behaviour and squeal generation of disc brakes at low speeds, Proceedings of the Institution of Mechanical Engineers D 215 (D12), pp. 1245-1256, 2001.

[2] Kinkaid, N.M., O'Reilly, O.M. \& Papadopoulos, P., Automotive disc brake squeal, Journal of Sound and Vibration, 267 (1), pp. 105-166, 2003.

[3] Rhee, S.K., Tsang, P.H.S. \& Wang, Y.S., Friction-induced noise and vibration of disc brakes, Wear, 133, pp. 39-45, 1989.

[4] Lorang, X., Foy-Margiocchi, F., Nguyen, Q.S \& Gautier, P.E., TGV disc brake squeal, Journal of Sound and Vibration, 293, pp. 735-746, 2006.

[5] Brizard, D., Chiello, O. Sinou, J.J. \& Lorang, X., Performance of some reduced bases for the stability analysis of a disc/pads system in sliding contact, Journal of Sound and Vibration, 293, pp. 735-746, 2011.

[6] Fritz, G., Sinou, J.J., Duffal, J.M. \& Jézéquel, L., Effects of damping on brake squeal coalescence patterns-application on a finite element model, Mechanics Research Communications, 34, pp. 181-190, 2007.

[7] Sinou, J.J., Fritz, G. \& Jézéquel, L., The role of damping and definition of the robust damping factor for a self-exciting mechanism with constant friction, Journal of Vibration and Acoustics, 129, pp. 297-306, 2007.

[8] Liu, P., Zheng, H., Cai, C., Wang, Y.Y., Lu, C., Ang, K.H. \& Liu, G.R., Analysis of disc brake squeal using the complex eigenvalue method, Applied Acoustics, 68, pp. 603-615, 2006.

[9] Oberst, S. \& Lai, J.C.S., Numerical methods for simulating brake squeal noise, Proceedings of $20^{\text {th }}$ International Congress on Acoustics, ICA 2010, Sydney, Australia, 2, pp. 1505-1516, 2010.

[10] Kang, J., Finite element modelling for the investigation of in-plane modes and damping shims in disc brake squeal, Journal of Sound and Vibration, 331(9), pp. 2190-2202, 2012.

[11] Festjens, H., Gaël, C., Franck R., Jean-Luc, D. and Remy, L., Effectiveness of multilayer viscoelastic insulators to prevent occurrences of brake squeal: A numerical study, Applied Acoustics, 73(11), pp. 1121$1128,2012$.

[12] Heckl, M.A., \& Huang, X.Y., Curve squeal of train wheels, part 3: active control, J. of Sound and Vibration, 229(3), pp. 709-735, 2000.

[13] Heckl, M.A., Curve squeal of train wheels, part 2: which wheel modes are prone to squeal? J. of Sound and Vibration, 229(3), pp. 695-707, 2000.

[14] Heckl, M.A. \& Abrahams, I.D., Curve squeal of train wheels, part 1: mathematical model, J. of Sound and Vibration, 229(3), pp. 669-693, 2000.

[15] Liu, X. \& Meehan, P. A., Investigation of the effect of lateral adhesion and rolling speed on wheel squeal noise, Proc. IMechE Part F: J. Rail and Rapid Transit, 227(5), pp. 469-480, 2003.

[16] Glocker, C., Cataldi-Spinola, E. \& Leine, R.I., Curve squealing of trains: Measurement, modelling and simulation, Journal of Sound and Vibration, 324, pp. 365-386, 2009. 
[17] Hsu, S.S., Huang, Z., Iwnickl, S.D., Thompson, D.J., Jones, C.J.C., Xie, G. $\&$ Allen, P.D., Experimental and theoretical investigation of railway wheel squeal, Proc. IMechE Part F: J. Rail and Rapid Transit, Special Issue Paper, pp. 59-73, 2007.

[18] Vincent, A., Koch, J.R., Chollet, H. \& Guerder, J.Y., Curve squeal of urban rolling stone-Part 1: State of the art and field measurements, Journal of Sound and Vibration, 293, pp. 691-700, 2006.

[19] Chollet, H., Ayasse, J.B., Vincent, A. \& Koch, J.R., Part 3: Theoretical model, Journal of Sound and Vibration, 293, pp. 710-727, 2006.

[20] Brunel, J.F., Dufrenoy, P., Nait, M., Munoz, J.L. \& Demilly, F., Transient models for curve squeal noise, Journal of Sound and Vibration, 293, pp. 758-763, 2006.

[21] Monk-Steel, A.D., Thompson, D.J., de Beer, G.G. \& Janssens, M.H.A., An investigation into the influence of longitudinal creepage on railway squeal noise due to lateral creepage, Journal of Sound and Vibration, 293, pp. 766-776, 2006.

[22] Chen, G.X., Xiao, J.B., Liu, Q.Y. \& Zhou, Z.R., Complex eigenvalue analysis of railway curve squeal, Noise and Vibration Mitigation, NNFM99, pp. 433-439, 2008.

[23] ABAQUS Analysis User's manual, Ver. 6.5, Vol. II. 6.3.6. 